\title{
STUDY OF SODIUM AND POTASSIUM IMBALANCE IN NEWLY DIAGNOSED HYPERTENSION
}

\author{
Hari Om Gupta1, Ravi Prakash Pandey², Shafeek $A^{3}$, Manoj Indurkar ${ }^{4}$
}

1 Professor, Department of Medicine, S. S. Medical College, Rewa, Madhya Pradesh, India.

${ }^{2}$ Associate Professor, Department of Medicine, S. S. Medical College, Rewa, Madhya Pradesh, India.

3 Postgraduate Student, Department of Medicine, S. S. Medical College, Rewa, Madhya Pradesh, India.

${ }^{4}$ Professor and HOD, Department of Medicine, S. S. Medical College, Rewa, Madhya Pradesh, India.

\begin{abstract}
BACKGROUND

Hypertension is one of the leading causes of death and disability among adults all over the world. It remains the major risk factor for coronary, cerebral and peripheral vascular disease. Essential hypertension comprises more than 90\% of hypertension. Hypertension is an emerging health problem in India. When majority of people come to know that they have hypertension they have already advanced into a stage with target organ damage- a fatal stroke or myocardial infarction or irreversible renal failure. Unfortunately, even in developed countries like United States, 50 million people have hypertension.

Aim of the study- To study serum sodium and potassium levels and correlate them with the blood pressure in newly detected hypertension.
\end{abstract}

\section{MATERIALS AND METHODS}

This was a cross sectional study conducted in the department of General Medicine at S.S. Medical College Rewa M.P. over a period of one year. Both inpatients and outpatients were included in the study.

\section{RESULTS}

In our study, out of 250 patients, 133 were in stage 1 hypertension (53.2\%) and 102 patients were in stage 2 hypertension (40.8\%). Very small proportions (6\%) were having isolated systolic hypertension. Serum sodium was higher in both stage $1 \& 2$ hypertension and serum potassium was lower in both stage-1 \& -2 hypertension.

\section{CONCLUSION}

Serum sodium was significantly higher among newly diagnosed hypertensives and also correlated positively with levels of blood pressure. Serum potassium was significantly less among newly diagnosed hypertensives and it correlated negatively with levels of blood pressure.

\section{KEY WORDS}

Newly Diagnosed Hypertension, Serum Sodium, Serum Potassium.

HOW TO CITE THIS ARTICLE: Gupta HO, Pandey RP, Shafeek A, et al. Study of sodium and potassium imbalance in newly diagnosed hypertension. J. Evolution Med. Dent. Sci. 2018;7(52):5516-5519, DOI: $10.14260 /$ jemds/2018/1221

\section{BACKGROUND}

Hypertension ${ }^{[1]}$ is one of the most common disease afflicting humans throughout the world. Because of the associated morbidity and mortality and the cost to society, hypertension is an important public health challenge. Over the past several decades, extensive research, widespread patient education, and a concerted effort on the part of health care professionals have led to decreased mortality and morbidity rates from the multiple organ damage, arising from years of untreated hypertension. Hypertension is the most important modifiable risk factor for coronary heart disease, stroke, congestive heart failure, end-stage renal disease, and peripheral vascular disease. Therefore, health care professionals must not only identify and treat patients with hypertension but also promote a healthy lifestyle and preventive strategies to decrease the prevalence of hypertension in the general

'Financial or Other Competing Interest': None.

Submission 11-11-2018, Peer Review 07-12-2018,

Acceptance 12-12-2018, Published 24-12-2018.

Corresponding Author:

Dr. Ravi Prakash Pandey,

F-18, Doctor's Colony,

S. S. Medical College, Campus,

Rewa, Madhya Pradesh, India.

E-mail: drraviprakashpandey@gmail.com

DOI: $10.14260 /$ jemds/2018/1221 population. The diagnosis and treatment of hypertension[2] in the young which constitutes one of the major health challenges today because of the high percentage of potentially curable chance if the cause could be found. Indeed, intensive study and investigations are required to un-ravel the underlying cause.

Hypertension is an emerging health problem in India. When majority of people come to know that they have hypertension they have already advanced into a stage with target organ damage a fatal stroke or myocardial infarction or irreversible renal failure. ${ }^{[3]}$ Our distant ancestors consumed a low-sodium, high-potassium diet.[4] and accordingly your kidneys are adapted to conserve sodium and excrete potassium. ${ }^{[5]}$

In a country like India, people will have a diet rich in sodium and poor in potassium. We have known for over 2000 years that an acute high dietary sodium intake in the form of a salty[6] meal, results in a temporary increase in blood pressure and is associated with several other important diseases.[7] In developed countries, contemporary diets are high in sodium, primarily resulting from the salt added to manufactured foods and low in good sources of potassium such as vegetables and fruit.

Many studies have shown that a positive correlation exists between serum sodium and blood pressure and a negative correlation exists between serum potassium and 
level of $140(47.0 \%)$ and minimum number of patients in stage II hypertension in the sodium level of $<135$ (8.8\%).

\begin{tabular}{|c|c|c|c|c|c|c|c|c|}
\hline \multirow{2}{*}{$\begin{array}{c}\text { Potassium } \\
\text { Level }\end{array}$} & $\begin{array}{c}\text { Stage 1 } \\
\text { Hyper- } \\
\text { tension }\end{array}$ & $\begin{array}{c}\text { Stage 2 } \\
\text { Hyper- } \\
\text { tension }\end{array}$ & $\begin{array}{c}\text { Isolated } \\
\text { Systolic } \\
\text { Hyper- } \\
\text { tension }\end{array}$ & \multicolumn{2}{c|}{ Total } \\
\cline { 2 - 10 } & No & $\%$ & No & $\%$ & No & $\%$ & No & $\%$ \\
\hline$<3.5$ & 58 & 43.6 & 32 & 31.3 & 8 & 53.3 & 98 & 39.2 \\
\hline $3.5-4.5$ & 35 & 26.3 & 50 & 49.01 & 4 & 26.6 & 89 & 35.6 \\
\hline $4.5-5.5$ & 22 & 16.54 & 15 & 14.7 & 2 & 13.33 & 39 & 15.6 \\
\hline$>5.5$ & 18 & 13.53 & 5 & 4.9 & 1 & 6.6 & 24 & 9.6 \\
\hline Total & 133 & 100.0 & 102 & 100.0 & 15 & 100.0 & 250 & 100.0 \\
\hline \multicolumn{8}{|c|}{$\mathrm{p}=0.0112$} \\
\hline Association between Potassium and Systolic Hypertension \\
\hline \multicolumn{10}{|c|}{16.53} \\
\hline
\end{tabular}

Distribution of systolic hypertension according to potassium levels was found to be negatively correlated and statistically significant $(p=0.0112)$. the maximum no of patients had potassium levels of $<3.5(39.2 \%)$ and minimum number of patients had potassium level of more than 5.5 (9.6\%). In stage 1 Hypertension, maximum number of hypertensive patients had $<3.5$ potassium levels and in stage 2 Hypertension maximum patients had levels between 3.5 to 4.5. In case of isolated hypertension maximum patients had potassium levels of $<3.5$. (53.3\%). Minimum no of patients had potassium levels of more than $>5.5(9.6 \%)$. In case of stage 1 Hypertension minimum patients had potassium levels of $>5.5(13.53 \%)$ In case of stage 2 Hypertension minimum no patients had potassium levels of $>5.5$ (4.9\%). Minimum no of patients in isolated Hypertension had potassium levels of $>$ $5.5(6.6 \%)$.

\begin{tabular}{|c|c|c|c|c|c|c|}
\hline $\begin{array}{c}\text { Potassium } \\
\text { level }\end{array}$ & $\begin{array}{c}\text { Stage 1 } \\
\text { hyper- } \\
\text { tension }\end{array}$ & $\%$ & $\begin{array}{c}\text { Stage 2 } \\
\text { hyper- } \\
\text { tension }\end{array}$ & \% & Total & $\%$ \\
\hline$<3.5$ & 56 & 42.1 & 29 & 28.4 & 85 & 36.17 \\
\hline $3.5-4.5$ & 32 & 24.06 & 53 & 51.9 & 85 & 36.17 \\
\hline $4.5-5.5$ & 24 & 18.04 & 13 & 12.74 & 37 & 15.74 \\
\hline$>5.5$ & 21 & 15.78 & 7 & 6.8 & 28 & 11.91 \\
\hline Total & 133 & $\mathbf{1 0 0 . 0}$ & $\mathbf{1 0 2}$ & $\mathbf{1 0 0 . 0}$ & $\mathbf{2 3 5}$ & $\mathbf{1 0 0}$ \\
\hline \multicolumn{7}{|c|}{$\mathrm{p}=0.0018$} \\
\hline$\chi 315.00$ \\
\hline \multicolumn{7}{|c|}{ Association between Potassium and Diastolic } \\
Hypertension \\
\hline
\end{tabular}

Distribution of diastolic hypertension according to potassium levels was negatively correlated \& was found to be statistically significant $(\mathrm{p}=0.0018)$ The maximum no patients lie in the potassium level $<3.5(34 \%)$ and minimum number of patients lie in the potassium level of more than 5.5 In stage 1 Hypertension maximum no of patients lie in potassium level $<3.5(42.1 \%)$. In stage 2 Hypertension maximum patients lie in potassium level $3.5-4.5(51.9 \%)$. Minimum no of patients lie in potassium level $>5.5(11.2 \%)$. Minimum no of patients in stage 1 hypertension lie in potassium level $>5.5$ (15.78\%). Minimum No of patients in stage 2 hypertension lie in potassium level $>5.5(6.8 \%)$.

\section{DISCUSSION}

Hypertension is one of the leading causes of death and disability among adults all over the world. Hypertension the most common form of cardiovascular disease is present in nearly $25 \%$ of adults and increases in prevalence with age. It remains the major risk factor for coronary, cerebral and peripheral vascular disease.[8] Essential hypertension comprises more than $90 \%$ of hypertension. Patients were studied on the basis of clinical parameters and simple biochemical investigations. Serum sodium and potassium was done for all the patients. In our part of the country, there is excessive intake of dietary salt. But in spite of that not everyone has essential hypertension.[9] The rarity of hypertension among those consuming large amount of salt may probably be related to chronic adaptation of body system towards renal clearance of sodium. However, this aspect of chronic adaptation of sodium handling by kidneys requires further molecular studies. So in addition to the hereditary predisposition and high sodium intake and lower potassium intake, the renal handling of these cations also play an important role in the pathogenesis of essential hypertension.[10] Salt intake was more in the tropical countries by and large in order to overcome sodium loss through sweating. In modern days the consumption of salt is more than earlier days in view of various food preparations or a combination of them, as man is tuned more to taste of the food. Combination of food materials requires additional salt. As a result, people consume more than actually required (2 vs. 8-10 g/day/person). Such an amount of salt consumption contributes for the development of hypertension in a genetically susceptible population.[11]

In the present study serum sodium is positively correlated with levels of blood pressure and it is statistically significant. Most of the patients $(>58.4 \%$ ) were in above 140 sodium level and minimum number of patients were in the range of sodium <135 (12.4\%). In stage 1 hypertension maximum number of patients $(48.51 \%)$ are in range of 140 145 sodium level and minimum number of patients were in less than 135 (18.7\%) sodium level. In stage 2 hypertension most of the Patients (58.82\%) were in the level of 140-145. In stage 2 minimum number of patients $(5.8 \%)$ at the level of less than 135 . In isolated hypertension $80 \%$ of the patients were in above 140 sodium level. ( $\mathrm{P}$ value $<0.0001$ )

In the present study serum sodium is positively correlated with levels of blood pressure and it is statistically significant. Most of the patients $(41.6 \%)$ were at the level of sodium 140-145. In stage 1 hypertension $60 \%$ were above 145 sodium level. In stage 1 hypertension Minimum number of patients $(12.3 \%)$ are in less than 135 level. In stage 2 hypertension $45 \%$ patients are at level of above 140 . In stage 2 hypertension minimum number of patients $(8.8 \%)$ are at the level of less than 135 ( $\mathrm{P}$ value=0.0153).

Our study is also supported by Anand Kumar et al. (2017).[12] According to this study serum sodium was significantly more among hypertensive and also correlated positively with levels of blood pressure. Serum potassium was significantly less among hypertensives and is correlated negatively with blood pressure.

Our study is also supported by Kawasaki et al (1978),[13] found the effect of very low sodium (10 meq/day) or high (200 meq/day) dietary sodium intake on blood pressure in patients with essential hypertension. They found that half of the patients fed with high dietary sodium intake displayed rise in blood pressure more than 10 percent.[14]

In present study serum potassium is negatively correlated with levels of blood pressure and it is statistically significant. In the present study most of the patients (39.2\%) are at the level of potassium less than 3.5. In stage 1 hypertension most of the patients $(70 \%)$ were in the level of less than 4.5 . In 
stage 1 minimum number of patients (13.5\%) were in above 5.5 potassium level. In stage 2 hypertension most of the patients $(80 \%)$ were at level of less than 4.5. Minimum number of patients $(4.9 \%)$ are at the level of more than 5.5.

In isolated hypertension most of the patients (53.3\%) were at level less than 3.5. Minimum number of patients $(6.6 \%)$ were at the level of more than 5.5 (P value $=0.0112$ )

In present study serum potassium is negatively correlated with levels of blood pressure and it is statistically significant. In most of the patients (36\%) were at the level of potassium less than 3.5. Minimum number of patients $(11.2 \%)$ were at level of more than 5.5 potassium level. In stage 1 hypertension most of the patients $(42.1 \%)$ were in potassium level less than 3.5 and minimum number of patients $(15.78 \%)$ were in the potassium level above 5.5 . In stage 2 hypertension most of the patients $(51.9 \%)$ at the potassium level 3.5 to 5.5. Minimum number of patients $(6.8 \%)$ at the level of more than 5.5 potassium. ( $\mathrm{P}$ value $=0.018$ )

Our study was supported by Jan et al (2006), Srinagar, Kashmir. In this study serum sodium was higher in hypertensive group and considered to be factor responsible for the causation or perpetuation of blood pressure.[14]

A study was carried out by Bulpitt et al (1981).[15] According to them decreasing plasma potassium $1 \mathrm{mmol} / \mathrm{L}$ were associated with increase in systolic and diastolic blood pressure by $7 / 4 \mathrm{mmHg}$ in women and $4 / 2 \mathrm{mmHg}$ in men respectively.

A study was carried out by Sathvika et al (2017).[16] According to them serum sodium was more among hypertensives and it is independent of associated risk factors and gender. Serum sodium levels correlated positively with levels of blood pressure. Serum potassium was significantly less among hypertensives and it correlated negatively with blood pressure.[16]

\section{CONCLUSION}

Essential hypertension is the major risk factor for coronary, cerebral and renal vascular diseases. Aetiology for essential hypertension is not known. Many theories have been postulated. The present study attempts to focus the serum sodium and potassium levels among newly diagnosed essential hypertensives who were free from any other illnesses or under any medication and to correlate electrolyte status with the blood pressure. Serum sodium was significantly more among hypertensives and also correlated positively with the level of blood pressure. Serum potassium was significantly less among hypertensives and it correlated negatively with blood pressure. Changing life style have modified the food habits, making people to consume food rich in sodium but low in potassium. As a result, in genetically susceptible population when exposed to high sodium content coupled with low potassium in their diet, hypertension becomes overt.

\section{REFERENCES}

[1] Chobanian AV, Bakris GL, Black HR, et al. The seventh report of the Joint National Committee on prevention, detection, evaluation and treatment of high blood pressure: the JNC 7 Report. JAMA 2003;289(19):2560-72.

[2] Panja M, Kumar S, Sarkar CN, et al. Hypertension in the young in Eastern India. Indian Heart Journal 1996;48(6):663-6.

[3] Tierney LM, Masse BM, Papadakis MA. Current medical diagnosis \& treatment. 45 th edn. USA: McGraw-Hill Company 2006: p. 419-45.

[4] Eaton SB, Konner M. Paleolithic nutrition. A consideration of its nature and current implications. N Engl J Med 1985;312(5):283-9.

[5] Adrogué HJ, Madias NE. Sodium and potassium in the pathogenesis of hypertension. N Eng J Med 2007;356(19):1966-78.

[6] He FJ, MacGregor GA. A comprehensive review on salt and health and current experience of worldwide salt reduction programmes. J Hum Hypertens 2009;23(6):363-84.

[7] Veith I. The Yellow Emperor's Classic of internal medicine. $2^{\text {nd }}$ edn. Berkeley, CA, USA: University of California Press 2002.

[8] Gupta R. Defining hypertension in the Indian population. National Medical J India 1997;10:13943.

[9] Gupta R, Sharma AK, Gupta VP, et al. c17(8):53540.

[10] Gupta R. Trends in hypertension epidemiology in India. J Human Hypertension 2004;18(2):73-8.

[11] Gupta R, Al-Odat NA, Gupta UP. Hypertension epidemiology in India: meta-analysis and fifty year prevalence rates and blood pressure trends. J Human Hypertens 1996;10(7):465-72.

[12] Kumar A, Prasad SD. Evaluation of serum sodium and potassium levels in newly diagnosed patients of essential hypertension at Rims, Ranchi, Jharkhand, India. IOSR Journal of Dental and Medical Sciences (IOSR-JDMS) 2017;16(9):16-9.

[13] Kawasaki T, Delea CS, Bartter FC, et al. The effect of high-sodium and low-sodium intakes on blood pressure and related variables in human subjects with idiopathic hypertension. Am J Med 1978;64(2):193-8.

[14] Gupta PC, Gupta R, Pednekar MS. Hypertension prevalence and blood pressure distribution among 88,653 subjects in Mumbai, India. J of Human Hypertension 2004;18(12):907-10.

[15] Bulpitt CJ, Shipley MJ, Semmence A. Blood pressure and plasma sodium and potassium. Clin Sci (Lond) 1981;61 Suppl 7:S85-S7.

[16] Murugan, Sathvika. Serum sodium and potassium levels in newly diagnosed essential hypertensive patients in Government Dharmapuri Medical College, Dharmapuri. IAIM 2017;4(7):167-72. 